\title{
Ground motion scenarios for the 1997 Colfiorito, central Italy, earthquake
}

\author{
Antonio Emolo $\left({ }^{1}\right)$, Giovanna Cultrera $\left({ }^{2}\right)$, Gianlorenzo Franceschina $\left({ }^{3}\right)$, Francesca Pacor $\left({ }^{3}\right)$, Vincenzo \\ Convertito $\left({ }^{4}\right)$, Massimo Cocco $\left({ }^{2}\right)$ and Aldo Zollo $\left({ }^{1}\right)$ \\ $\left.{ }^{1}\right)$ Dipartimento di Scienze Fisiche, Università degli Studi «Federico II», Napoli, Italy \\ ${ }^{2}{ }^{2}$ Istituto Nazionale di Geofisica e Vulcanologia, Roma, Italy \\ ${ }^{(3)}$ Istituto Nazionale di Geofisica e Vulcanologia, Milano, Italy \\ $\left({ }^{4}\right)$ Istituto Nazionale di Geofisica e Vulcanologia - Osservatorio Vesuviano, Napoli, Italy
}

\begin{abstract}
In this paper we report the results of several investigations aimed at evaluating ground motion scenarios for the September $26^{\text {th }}, 1997$ Colfiorito earthquake $\left(M_{\mathrm{w}} 6.0,09: 40\right.$ UTC). We model the observed variability of ground motions and the directivity effect through synthetic scenarios which simulate an earthquake rupture propagating at constant rupture velocity $(2.7 \mathrm{~km} / \mathrm{s})$. We discuss the variability of kinematic source parameters, such as the nucleation position and the rupture velocity, and how it influences the predicted ground motions and it does not account for the total standard deviation of the empirical predictive model valid for the region. Finally, we used the results from the scenario studies for the Colfiorito earthquake to integrate the probabilistic and deterministic approaches for seismic hazard assessment.
\end{abstract}

Key words Colfiorito earthquake - kinematic source modelling - ground shaking scenarios

\section{Introduction}

Following the occurrence of the 1997 Umbria-Marche seismic sequence, several Italian research projects focused on this sector of the Apennines to promote a better understanding of the regional seismicity and seismic hazard. Among many others, two of them were funded by the Italian Department of Civil Defense (Dipartimento della Protezione Civile), namely «Development and Comparison among Methodologies for the Evaluation of Seismic Hazard in Seismogenic Areas: Application to

Mailing address: Dr. Antonio Emolo, Dipartimento di Scienze Fisiche, Università degli Studi «Federico II», via Cintia, 80126 Napoli, Italy; e-mail: antonio.emolo@na.infn.it the Central and Southern Apennines» (GNDT Project, 2000-2003) and «Shaking seismic scenarios in area of strategic and/or priority interest» (S3 Project, 2004-2006), hereinafter named GNDT and S3 projects. In the framework of these projects several research activities were focused on the simulation of ground motions for the Colfiorito main shock $\left(\mathrm{M}_{\mathrm{w}} 6.0\right.$, September $26^{\text {th }}$, 1997, 9:40 UTC, hereinafter the Colfiorito earthquake).

Despite the moderate-magnitude of this earthquake, the source signature on the pattern of observed ground motions is evident (Cultrera et al., 2008). Directivity effects characterize the recorded accelerograms, as shown in fig. 1. This figure illustrates the peak ground accelerations (PGAs) recorded during the Colfiorito earthquake as a function of the epicentral distance, and compares them with the empirical predictive model proposed for the area by Bindi et al. (2006). It is evident that the stations located north of the epicenter show peak accelerations systematically larger than the empirical 


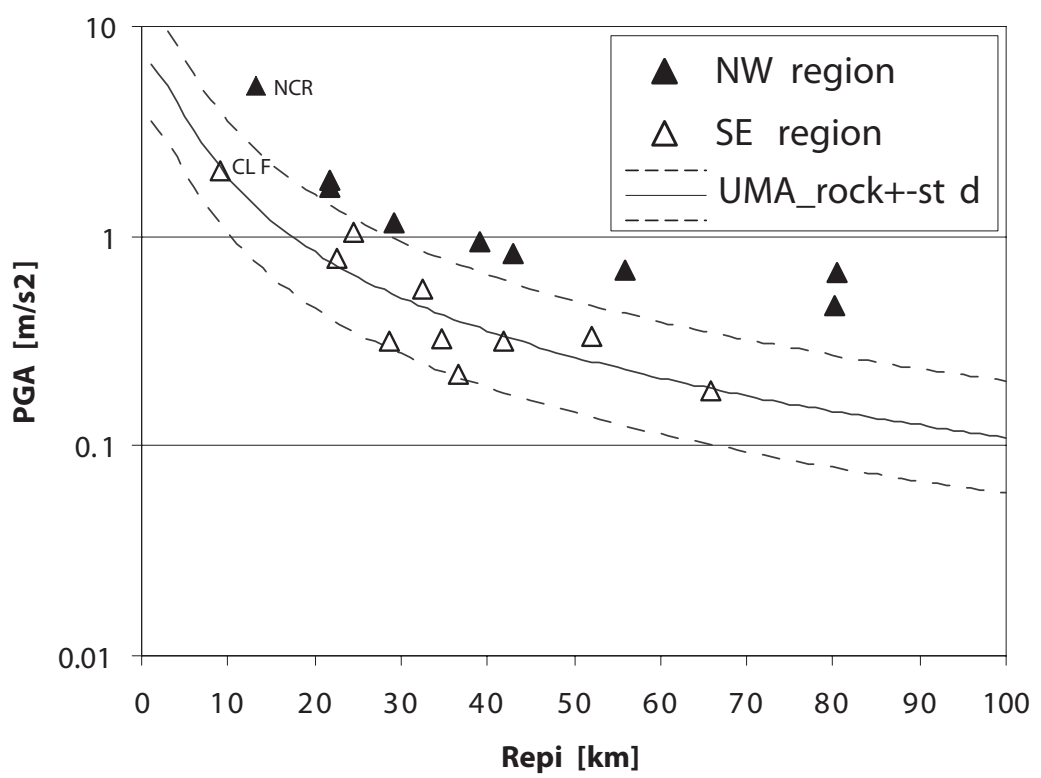

Fig. 1. Comparison of maximum horizontal PGAs recorded by accelerometers of the Italian Strong Motion Network with the UMA05 empirical predictive model of Bindi et al. (2006) for rock sites.

predictions, while the PGAs for the stations located south of the epicenter lie within one standard deviation of the empirical curves.

The anomalous high accelerations recorded at Nocera Umbra, more than $5 \mathrm{~m} / \mathrm{s}^{2}$ on the NS component, and at Colfiorito, about $2 \mathrm{~m} / \mathrm{s}^{2}$ on the WE component, have been associated with dominant site effects (Cultrera et al., 2003; Rovelli et al., 2001). However, the different source-to-receiver geometry as well as the behavior depicted in fig. 1, suggested us to investigate the effects related to the rupture history, such as the directivity effects. Indeed, a nearly NW rupture directivity can explain the observed variability of the ground motion around the fault. The relevance of this source effect during the earthquake has been confirmed by several studies aimed at imaging the kinematic rupture history through waveform modeling (e.g., Pino et al., 1999; Zollo et al., 1999; Capuano et al., 2000; Hernandez et al., 2004) as well as by the careful data analysis in Cultrera et al. (2008). The Colfiorito earthquake ruptured a normal fault SE striking along the
Apenninic direction. Most of the forward and inverse waveform modeling attempts rely on a similar position of the rupture nucleation point on the fault plane; it is located at depth close to the bottom of the fault and to the southernmost edge. The final slip distribution is characterized by a large slip patch in the southern part of the fault (fig. 2).

The results of these studies and the available information on the crustal velocity structure allowed us to design the numerical calculations for evaluating ground shaking scenarios for the target earthquake. This was done within the GNDT Project, whose main goal was to develop and compare different techniques for ground motion predictions. Several methodologies were applied to estimate the ground motion in terms of parameters of interest (e.g., peak values, spectral ordinates, and signal integral quantities) associated with the occurrence of a characteristic earthquake on an identified active fault. Indeed, the calculation of ground shaking scenarios commonly rely on the hypothesis of the characteristic earthquake model, which as- 


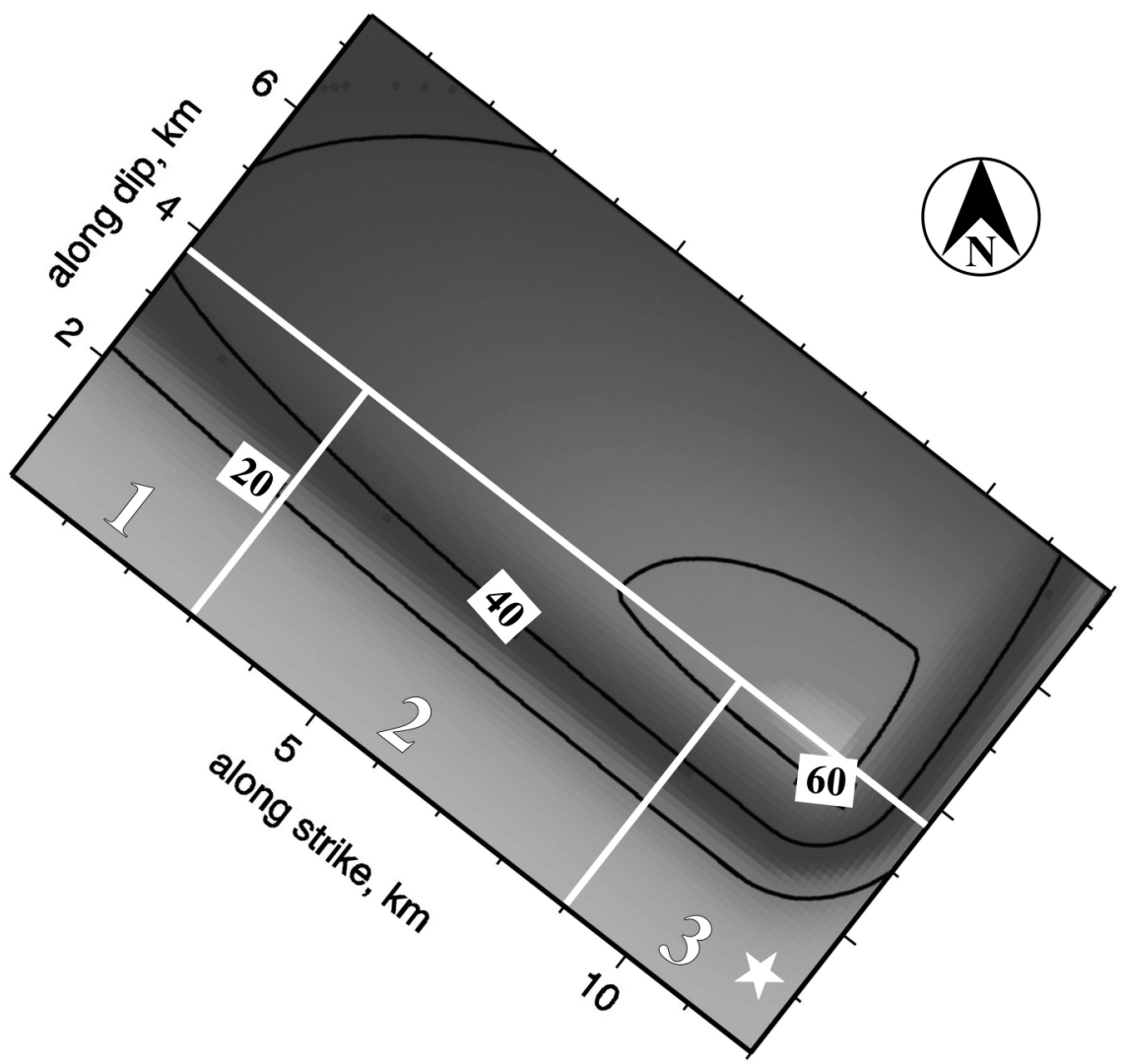

Fig. 2. Final slip distribution for the Colfiorito earthquake is represented as contour black lines. The units are $\mathrm{cm}$. The white star represents the position on the fault of the earthquake hypocenter. It is also shown (as white lines) the subdivision of the bottom half of the fault considered to name the different rupture processes. Nucleation points falling in the zone 1, 2, and 3 produce a SE unilateral, bilateral, and NW unilateral directivity, respectively.

sumes that earthquake ruptures repeatedly occur on the same fault (or fault system) with a nearly constant geometry, faulting mechanisms and maximum magnitude. These ideas are supported by numerous paleoseismic studies of active faults in different tectonic environment (e.g., Pantosti and Valensise, 1990). On the other hand, the rupture history (rupture nucleation, propagation and arrest) is not constant during several seismic cycles (that is, during subsequent rupture episodes on a given fault), because of the heterogeneity of the frictional and rheological properties and/or the geometrical complexities of fault zones. The recent 2004 Parkfield earthquake represents a key example of this behavior.

In this context, we have therefore assumed for our simulations that the large scale source features (i.e., fault geometry and position, focal mechanism and seismic moment) were $a$ priori known as a result of previous geological, geophysical and historical seismicity investigations, while the rupture history is unknown. The spatial variability of strong ground motions can depend on the heterogeneous distribution of different source model parameters (position of 
the rupture nucleation point, final slip, rupture velocity, slip duration, etc...) on the fault plane. This implies that a large number of synthetic seismograms must be computed to account for the complexity of the rupture history in order to obtain a representative collection of strong motion waveforms that can be used for hazard estimation. Therefore, numerous synthetic seismograms are computed for different rupture histories that are associated with a set of selected scenarios whose variability is designed to reflect the heterogeneity of the rupture process. The advantage of this approach is that the variability of the selected strong ground motion parameter at a given site can be described by the statistical quantities inferred from the large number of available simulations.

In this paper we summarize and discuss the major results on evaluating ground shaking scenarios for the Colfiorito earthquake. We also describe an original application of the method proposed by Convertito et al. (2006) to evaluate the seismic hazard in the study area. This method integrates the probabilistic and deterministic approaches and it is aimed at overcoming some of their respective limitations. The main novelty is that, in the frame of the classical PSHA approach, the contribution of earthquake rupture is evaluated through a deterministic simulation study. In this way, the time variable can be introduced in the deterministic scenarios in terms of return period and time of interest; moreover the source effects (geometry, radiation pattern, and directivity) are considered in the probabilistic approach.

\section{Ground motion simulation techniques}

The Colfiorito earthquake is modeled using different numerical approaches that simulate both approximated and full wave field. We will discuss here only the results from two approximated ground motion simulation techniques, i.e., the ASymptotic Method (hereinafter, ASM) and the Deterministic-Stochastic Method (hereinafter, DSM). Although these techniques are approximated, they are suitable for generating shaking scenarios close to an extended fault where the direct $\mathrm{S}$ wave field is generally dom- inant in amplitude with respect to the reflected, converted, and surface phases.

According to the ASM method (Zollo et al., 1997), the seismic wave field associated with the rupture of a finite fault (or fault system) is computed by solving numerically the representation integral. Since the technique is aimed at simulating the high frequency radiation, the Green functions are computed with the ray theory in a 1-D layered crustal medium (Farra et al., 1986). The fault is discretized in rectangular sub-faults whose size is chosen to reduce the numerical spatial aliasing. The space-time slip distribution on the fault is obtained assuming a ramp time function parameterized by the rupture time, the rise time, and the final slip for each sub-fault. In the original formulation of Zollo et al. (1997), the final slip distribution on the fault is computed in accordance to the $k$ squared model (Herrero and Bernard, 1994). The duration of the source time function is assumed to be lower than the maximum period of the synthetics (low-pass frequency). With this assumption, the slip velocity function can be considered as a Dirac delta function and then the omega-squared spectral behavior is preserved. In this simulation study, we simulated the ground motion up to a maximum frequency of $10 \mathrm{~Hz}$ and the corresponding rise time is chosen lower than $0.1 \mathrm{~s}$.

The other technique (DSM; Pacor et al., 2005) simulates an acceleration envelope by using the isochron formulation (Bernard and Madariaga, 1984; Spudich and Frazer, 1984) for a kinematic source model. The source process is defined by a nucleation point on a rectangular fault plane, from which the rupture propagates radially outward with a prescribed rupture velocity, and by a slip distribution defined in terms of final amount of slip for each sub-fault. The normalized envelope is then used to window a Gaussian noise signal which reproduces the phase incoherency of high frequency acceleration. The Fourier spectrum of the resulting time series is then multiplied by an omega-squared spectrum that contains source, attenuation, and site terms. The target spectrum is site-dependent because its corner frequency is computed as the inverse of the envelope duration as seen by the receiver; thus the corre- 
sponding acceleration time series will contain information about the directivity effects as modeled by the isochron formulation. The parameter «distance» also depends on the kinematic model, being defined by a spatial average over the fault plane and weighted on the envelope function in order to take into account each subfault contribution as perceived by the receiver (Pacor et al., 2005). DSM synthetic seismograms are reliable at high frequencies ( $>$ $0.5 \mathrm{~Hz}$ ); at lower frequencies the modeling is less accurate, especially in near source condition, where the omega-squared model is a too simple representation of the observed ground motion.

Both techniques compute the direct $\mathrm{S}$ wave field, that is dominant in the near-source distance range, allowing a fast computation of synthetic seismograms in the frequency band of engineering interest $[0.5-10 \mathrm{~Hz}]$. Conversely, they are not able to reproduce the wave-field related to complex propagation medium with lateral heterogeneities and soft layers. It is important to note that, since the two techniques implement different numerical representation of the rupture on a finite fault, the computed ground motions will differently depend on the various parameters used to describe the source kinematics. For instance, in DSM the use of the isochron formalism implies that the ground motion is directly related to the rupture time distribution on the fault. The ASM technique also accounts for the isochron distribution on the fault plane to sum up the contributions from the individual subfaults. Moreover, each elementary synthetic seismogram contains also the Green's function and, in particular, the radiation pattern. Differently, in the DSM method, the radiation pattern is accounted by an average coefficient.

\section{Scenarios for the Colfiorito fault}

The scenario study for the Colfiorito earthquake has been performed varying the kinematic parameters describing the rupture process on a fixed fault geometry, focal mechanism, seismic moment and crustal structure. More than 200 different rupture histories were simulated with both ASM and DSM techniques, using dif- ferent positions of the rupture nucleation, different constant rupture velocity values and different final slip distributions on the fault. The adopted fault-geometry, focal mechanism and seismic moment (table I) is inferred from the inversion of near source accelerometric data (Capuano et al., 2000). The crustal velocity model (table II) is derived, in the framework of the GNDT project, from the 3D velocity structure of the area, obtained by travel-times inversion using data from a dense temporary network. The attenuation parameters are taken from the study of Bindi et al. (2004). These authors computed a non-parametric inversion of strong motion records in the epicentral area of the 1997-1998 Umbria-Marche seismic se-

Table I. Parameters relative to the Colfiorito earthquake (modified after Capuano et al. 2000).

\begin{tabular}{cl}
\hline \hline Fault length & $12 \mathrm{~km}$ \\
Fault width & $7.5 \mathrm{~km}$ \\
Bottom depth & $8 \mathrm{~km}$ \\
Strike & $152^{\circ}$ \\
Dip & $38^{\circ}(\sim \mathrm{SW})$ \\
Slip & $-118^{\circ}$ \\
Seismic moment & $1.0 \times 10^{18} \mathrm{Nm}$ \\
Final slip mean value & $0.38 \mathrm{~m}$ \\
\hline
\end{tabular}

Table II. Crustal velocity model used in this simulation study.

\begin{tabular}{cccc}
\hline \hline $\begin{array}{c}\text { Layer top } \\
{[\mathrm{km}]}\end{array}$ & $\begin{array}{c}\mathrm{Vp} \\
{[\mathrm{km} / \mathrm{s}]}\end{array}$ & $\begin{array}{c}\mathrm{Vs} \\
{[\mathrm{km} / \mathrm{s}]}\end{array}$ & $\begin{array}{c}\text { Density } \\
{\left[\mathrm{gr} / \mathrm{cm}^{3}\right]}\end{array}$ \\
0 & 5.08 & 2.67 & 2.56 \\
3 & 5.75 & 3.03 & 2.65 \\
5 & 6.00 & 3.16 & 2.80 \\
7 & 6.25 & 3.30 & 2.80 \\
15 & 6.50 & 3.42 & 2.80 \\
\hline
\end{tabular}


quence. They found that the attenuation term can be modelled as

$$
A(f, r)=\frac{1}{r} \exp \left(\frac{-\pi f r}{Q_{s}(f) \beta}\right)
$$

where $\mathrm{r}$ is the epicentral distance, $\beta$, is the average $\mathrm{S}$-wave velocity and $\mathrm{Q}_{\mathrm{S}}$ is the $\mathrm{S}$-wave quality factor $\left(\mathrm{Q}_{\mathrm{s}}=49 \mathrm{f}^{0.9}\right.$, in the range $0.5-8.0 \mathrm{~Hz}$, and $Q_{s}=318$ for $f>8 \mathrm{~Hz}$. The high-frequency decay parameter $\mathrm{k}$ was set equal to $0.01 \mathrm{~s}$ (Bindi et al., 2004).

Synthetic seismograms were computed for each rupture history at a regular grid of 64 virtual receivers, regularly distributed in an area of about $60 \times 60 \mathrm{~km}^{2}$ around the fault; the distance between adjacent receivers was equal to $7.5 \mathrm{~km}$. In addition, the ground motion is simulated at seven near source sites, where permanent accelerometric stations recorded the Colfiorito main shock (ASSI, BVG, CLF, MFN, MTL, and NCR; see fig. 3).

As previously mentioned, we study the variability of predicted ground motions simulated with different rupture histories models, defined through different final slip distributions, rupture velocities and positions of the nucleation point on the fault.

Three values of the rupture velocities are chosen as representative of slow, average and fast ruptures $(2.4 \mathrm{~km} / \mathrm{s}, 2.7 \mathrm{~km} / \mathrm{s}$ and $2.9 \mathrm{~km} / \mathrm{s})$; in particular, the rupture velocity $2.7 \mathrm{~km} / \mathrm{s}$ corresponds to the 'true' value retrieved from data inversion by Capuano et al. (2000).

As far as the location of the nucleation point is concerned, we have considered three different potential areas for rupture initiation, all located on deeper half fault width, and corresponding to a bilateral rupture as well as to two unilateral ruptures propagating in opposite directions. For each rupture velocity value, rupture scenarios are grouped in 3 classes depending on the nucleation position (NW unilateral, bilateral and SE unilateral; fig. 2).

Figure 4 and fig. 5 display PGA and PGV maps, respectively, computed with both the numerical approaches and a constant rupture velocity of $2.7 \mathrm{~km} / \mathrm{s}$. The bottom panels in fig. 4 shows the PGA distribution computed with a rupture velocity equal to $2.4 \mathrm{Km} / \mathrm{s}$. Directivity effects are more pronounced in the DSM simulations, while the effect of radiation pattern is more evident in the ASM simulations. As expected the directivity effects are more prominent for unilateral propagating ruptures. Moreover, the rupture style determines the shape and extension of large peak values areas, whose maximum peaks are comparable in both techniques $\left(4 \mathrm{~m} / \mathrm{s}^{2}\right.$ for PGA and $0.3 \mathrm{~m} / \mathrm{s}$ per PGV); in particular, the ground motion variability observed for the Colfiorito earthquake is well reproduced when the NW unilateral rupture propagating with a $2.7 \mathrm{~km} / \mathrm{s}$ velocity is considered (in agreement with kinematic source models inferred by waveform inversions).

The effect on ground motion of two different rupture velocities can be also observed for PGA (top and bottom panels of fig. 4): the higher the rupture velocity the larger the peak values. Moreover, a larger rupture velocity causes a sort of magnification of those areas characterized by higher shaking levels. Figure 6 shows PGA values as a function of the azimuth measured from the fault strike as illustrated in the inset. Finite fault effects generate deviations of PGA azimuthal distribution from the constant scaling predicted by empirical regression laws (Sabetta and Pugliese, 1996, and Bindi et al., 2006): once the magnitude and the distance are fixed, the empirical models provide PGA values independent of azimuth.

The scaling of predicted PGA values as a function of epicentral distance and their comparison with the regional-specific predictive equation retrieved from the 1997-98 UmbriaMarche seismic sequence (UMA2005; Bindi et al., 2006) are displayed in fig. 7. Symbols identify the average values and the average \pm onestandard deviation for the PGAs computed through DSM. The solid and the dashed curves display the empirical attenuation law and the one-standard deviation interval, respectively. The agreement between the UMA2005 mean curve and the mean values obtained by the DSM ground motion scenarios is quite good even if the DSM values slightly underestimate the empirical ones. Note, however, that the simulated values are computed at bedrock sites while the empirical predictions are derived from data 


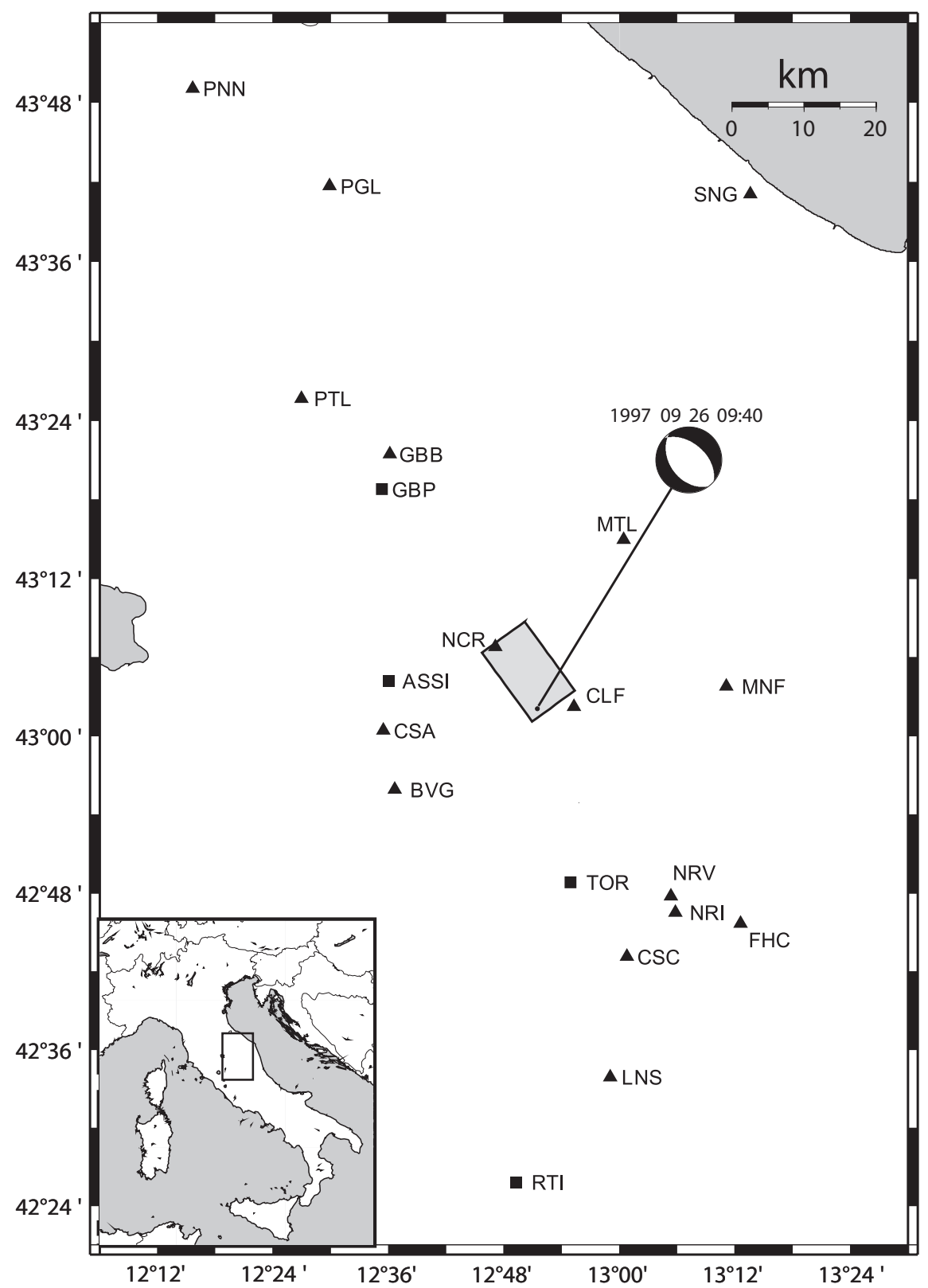

Fig. 3. Strong motion stations that recorded the Colfiorito earthquake (ASSI: Assisi, BVG: Bevagna, CLF: Colfiorito, CSA: Castelnuovo di Assisi, CSC: Cascia, FHC: Forca Canapina, GBB: Gubbio, GBP: Gubbio piana, LNS: Leonessa, MNF: Monte Fiegni, MTL: Matelica, NCR: Nocera Umbra, NRI: Norcia zona industriale, NRV: Norcia Altavilla, PGL: Pegli, PNN: Pennabilli, RTI: Rieti, SNG: Senigallia, TOR: Cerreto Torre). Triangles and squares correspond to digital and analog seismic stations, respectively. The fault surface projection (grey rectangle) and the focal mechanism of the Colfiorito earthquake, shown in the figure are from Capuano $e t$ al. (2000). 

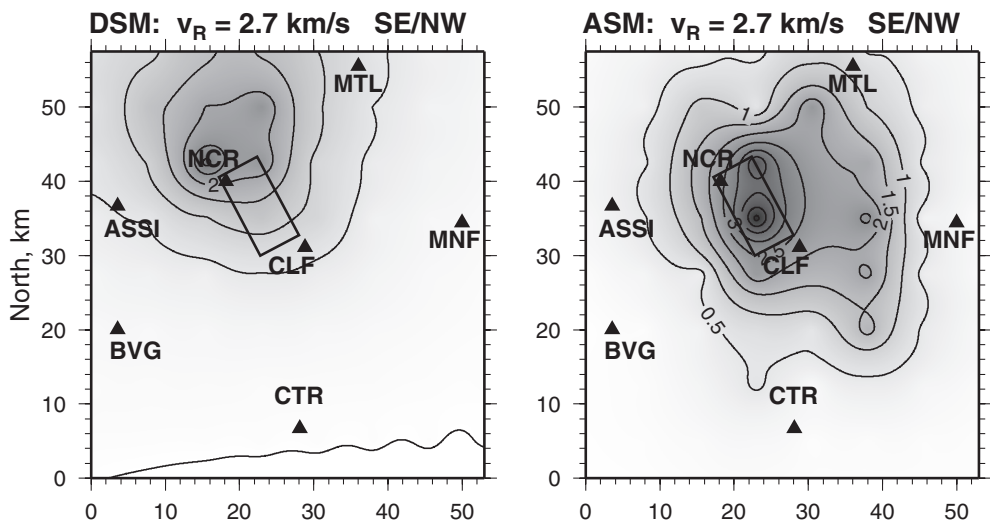

DSM: $v_{\mathrm{R}}=2.7 \mathrm{~km} / \mathrm{s}$ Bilateral

ASM: $v_{\mathrm{R}}=2.7 \mathrm{~km} / \mathrm{s}$ Bilateral
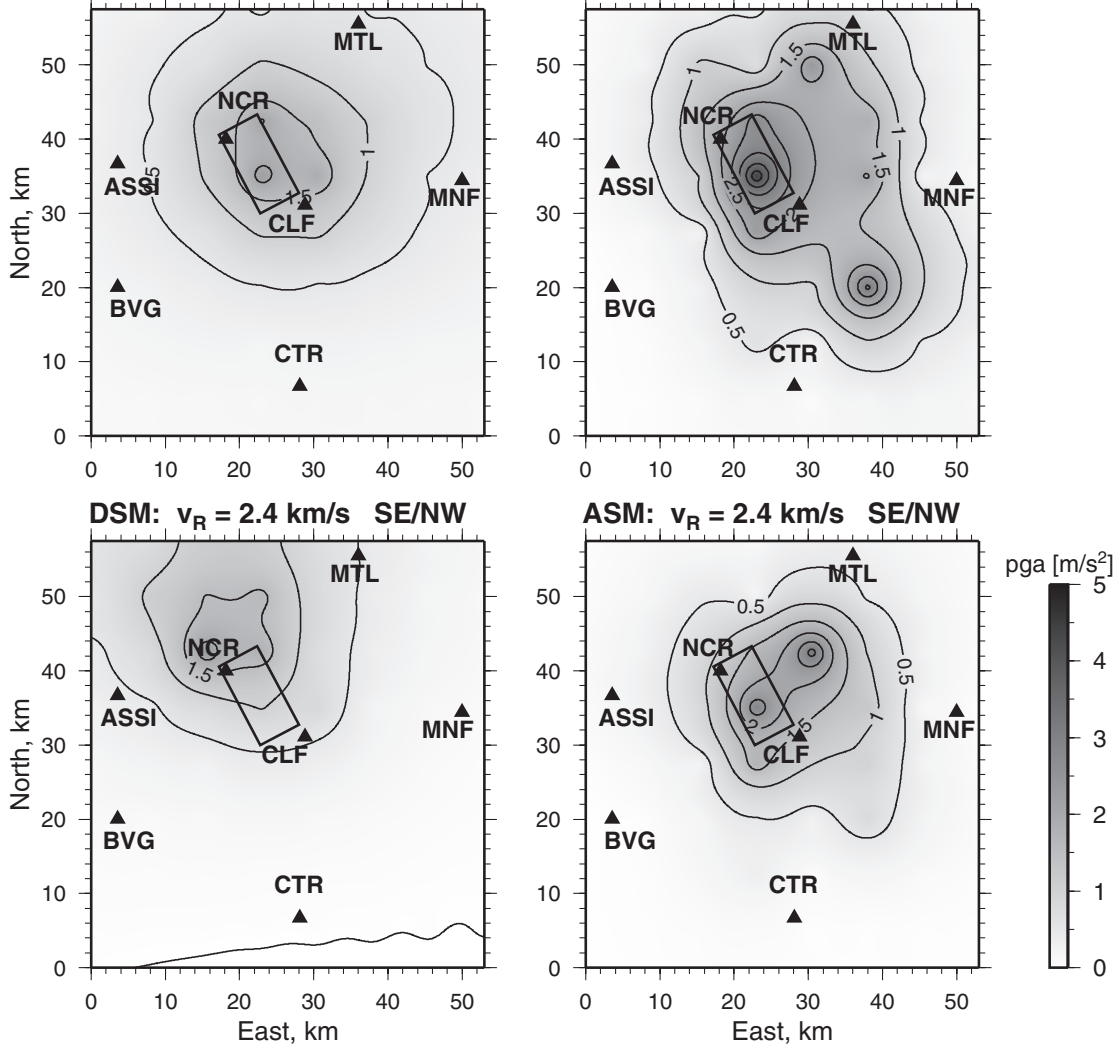

Fig. 4. Maps of mean synthetic PGA obtained for the Colfiorito earthquake using the DSM and the ASM simulations. Top panels: unilateral SE/NW nucleation for a constant rupture velocity of $2.7 \mathrm{~km} / \mathrm{s}$; middle panels: bilateral nucleation a constant rupture velocity of $2.7 \mathrm{~km} / \mathrm{s}$; bottom panels: unilateral SE/NW nucleation for a constant rupture velocity of $2.4 \mathrm{~km} / \mathrm{s}$. For all rupture models, the mean value of PGA is computed at each site from the distribution of peak values obtained from synthetics simulated by moving the nucleation point on the bottom half of the Colfiorito fault. 

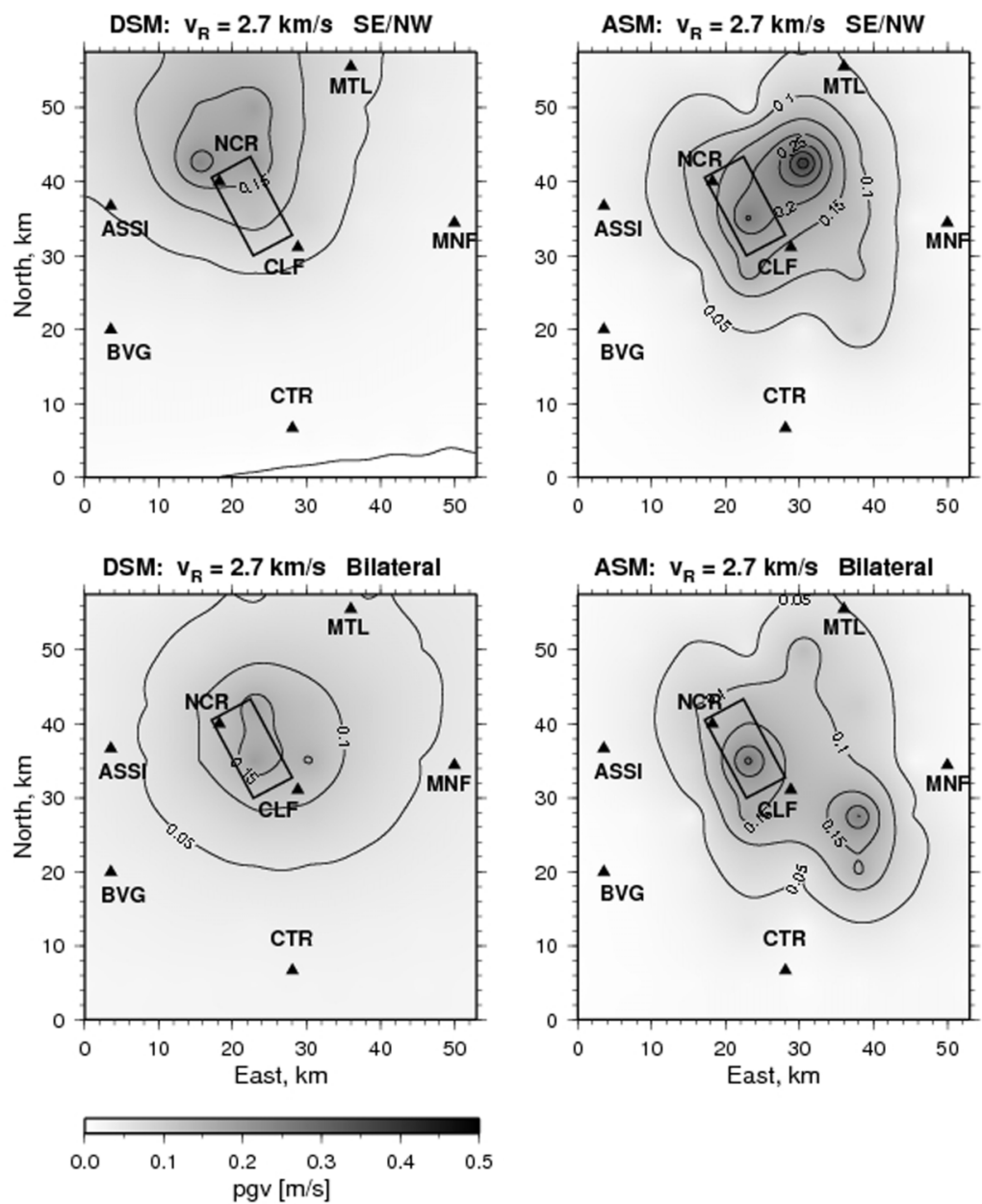

Fig. 5. Maps of mean synthetic PGV obtained for the Colfiorito earthquake using the DSM and the ASM simulations. Top panels: unilateral SE/NW nucleation for a constant rupture velocity of $2.7 \mathrm{~km} / \mathrm{s}$; bottom panels: bilateral nucleation for a constant rupture velocity of $2.7 \mathrm{~km} / \mathrm{s}$. For all rupture models, the mean value of PGV is computed at each site from the distribution of peak values obtained from synthetics simulated by moving the nucleation point on the bottom half of the Colfiorito fault.

recorded at rock sites that could be affected by amplification effects (Bindi et al., 2004; 2006).

The comparison of PGA standard deviations shown in fig. 7 indicates that numerical simulations produce a PGA variability greater than that resulting from the UMA2005 empirical regression law. This means that the variabil- ity introduced in kinematic source parameters (slip distributions, rupture velocity values and nucleation point position) produces ground motions whose peaks are comparable with the empirical models in terms of average values but with larger standard deviation. One possible explanation is that the simulations are performed 


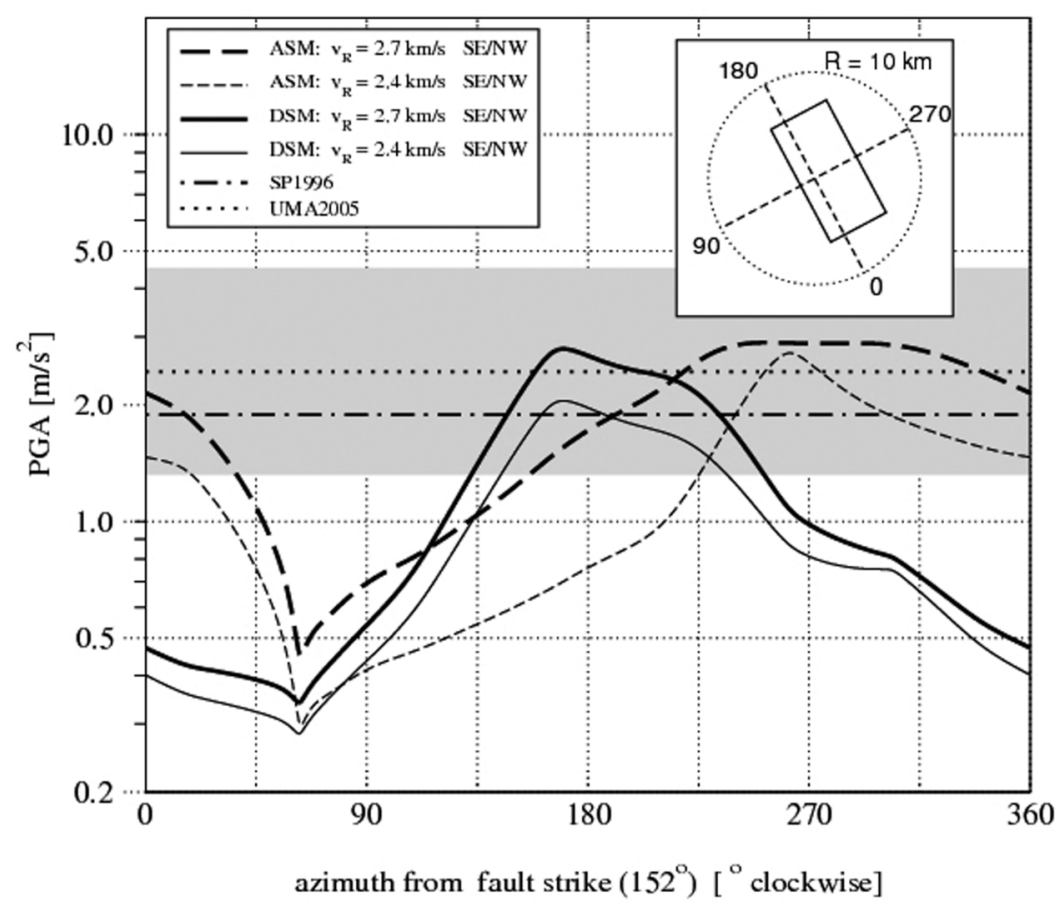

Fig. 6. PGA as a function of azimuth at $10 \mathrm{~km}$ epicentral distance predicted by synthetic simulations and by ground motion predictive equations. DSM and ASM simulations obtained with the unilateral SE/NW nucleation and with two values of the rupture velocity are compared with empirical predictions of Sabetta and Pugliese (1996) and UMA2005 (Bindi et al., 2006) for a M6 earthquake. Shaded area indicates \pm 1 std of UMA2005, and the inset shows the geometry adopted for the computation.

sampling many different rupture models of the same fault (more than 200) and using a very dense grid of observers.

The previous comparisons allowed us to select the source model which best fits the observed ground motions. Figure 8 shows the Fourier spectra of ground acceleration computed from time histories recorded at six near source stations during the Colfiorito earthquake.

The spectra are compared with the deterministic simulation performed by the DSM technique for an unilateral (toward NW) rupture model with $\mathrm{V}_{\mathrm{R}}=2.7 \mathrm{~km} / \mathrm{s}$.

The synthetic spectra include the site transfer functions estimated with different methods, depending on the available information: for CLF and MTL, the transfer functions were computed by 1D theoretical transfer functions (Rovelli et. al., 2001; Di Giulio et al., 2003; Luzi et al., 2005). Empirical transfer functions from the non-parametric spectral inversion (Bindi et al.; 2004) were adopted for ASSI and BVG. Finally the horizontal-to-vertical spectral ratios, computed on signal windows including the strong motion phases, were used to quantify the strong and complex local effects at NCR (Cultrera et al., 2003). No site effects are expected at MNF since the accelerometric station is located on rock site.

The agreement between observed and simulated spectra is quite good, especially at the MNF, CLF and NCR stations.

The mismatch at the other stations could be mainly ascribed to inappropriate transfer functions chosen to describe the local effects and to 


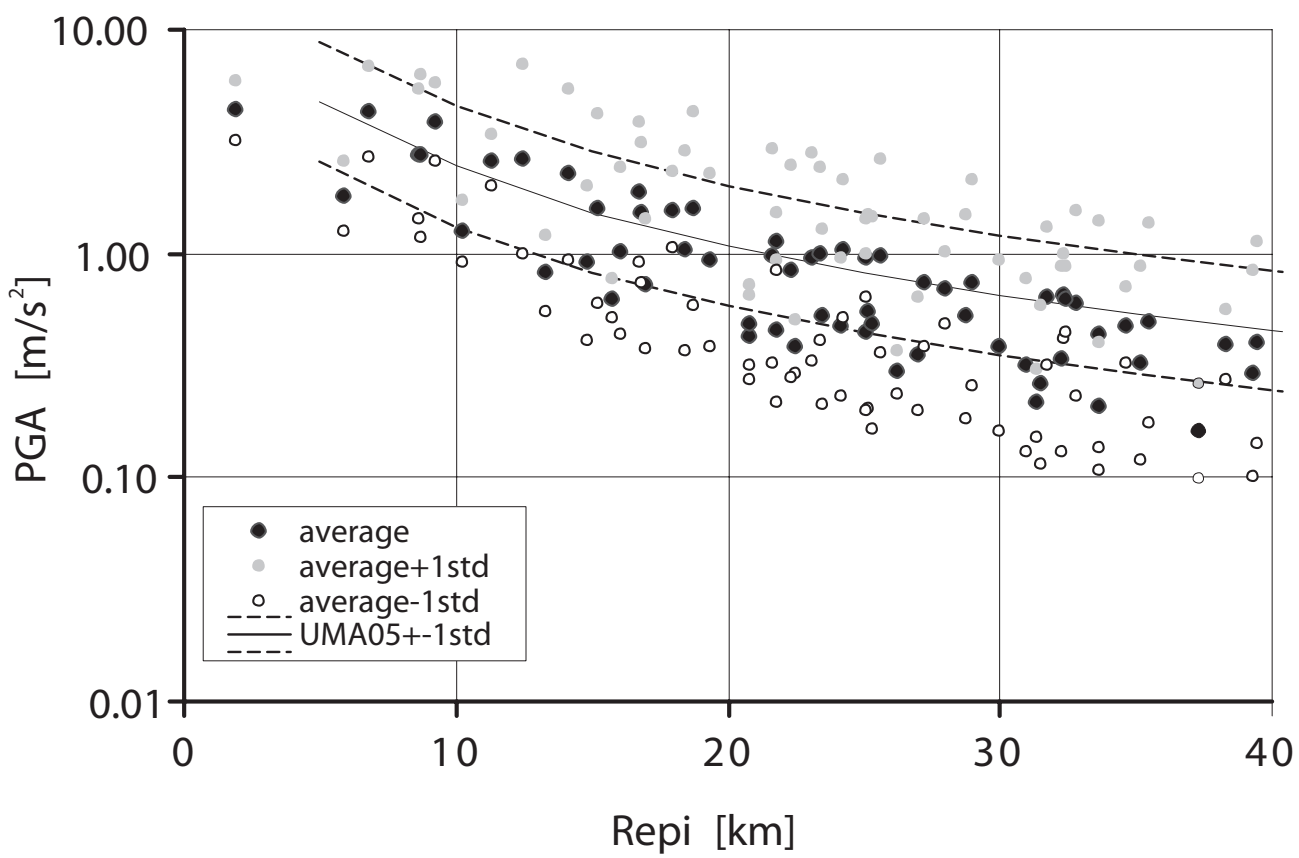

Fig. 7. Average PGA with \pm one standard deviation of the computed scenarios compared with UMA2005 ground motion prediction equation (Bindi et al., 2006).

the simplyfied simulation techniques. A detailed description of geotechnical site characterisation of these stations is reported in Luzi et al. (2005). BVG is located on deep lacustrine and alluvial deposits $(>30 \mathrm{~m})$ of the Valle Umbra basin and complex 2D and 3D effects are expected. MTL is installed on the alluvial deposits of a shallow basin with thickness $<30 \mathrm{~m}$ and the $1 \mathrm{D}$ profile is derived from penetrometric test data. Finally ASSI is installed next to the St. Francesco Cathedral and peak amplification could be related to interaction with the structure.

\section{Seismic hazard assessment: integrating probabilistic and deterministic approaches}

The results obtained with the deterministic simulations have been integrated in the probabilistic approach, following Convertito et al. (2006).
The Probabilistic Seismic Hazard Analysis (PSHA), developed by Cornell (1968), is widely used for evaluating the impact on earthquakes-prone areas associated with the occurrence of seismic events. The PSHA technique is largely applied in regions where the characteristics of the seismogenetic structures, responsible for large earthquakes, are not well known and then the application of deterministic approaches to the seismic hazard is not feasible. Moreover, when a single causative fault and a maximum-magnitude earthquake occurring on it are considered, it is not easy to define a recurrence relationship and the activity rate due to the non-completeness of seismic catalogues. To overcome these limitations, Convertito et al. (2006) compute the probability of occurrence of earthquakes by assuming the characteristic earthquake model (Schwartz and Coppermith, 1984), while the activity rate is obtained by the Youngs and Coppersmith (1985) approach. 

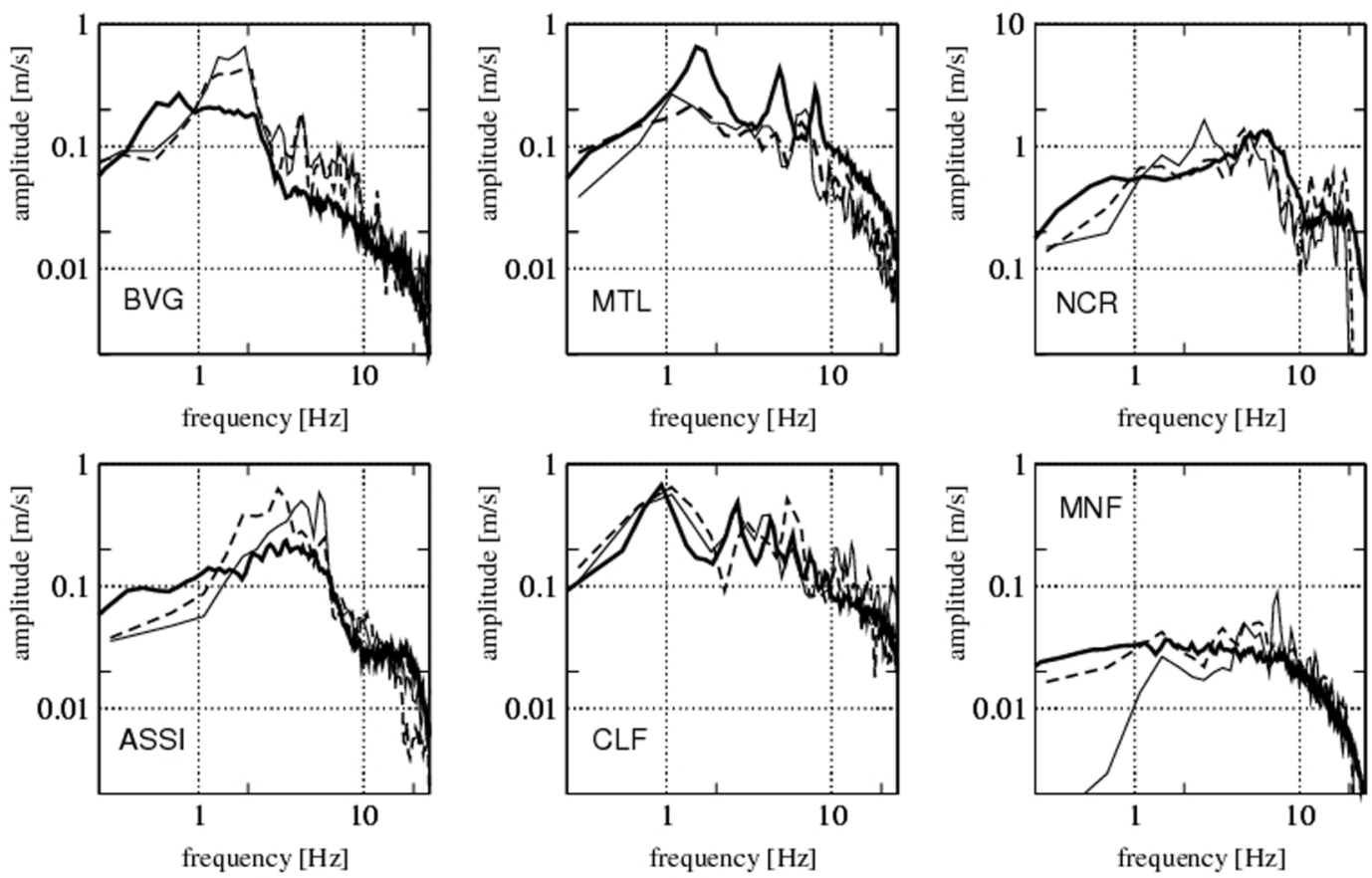

Fig. 8. Comparison of DSM synthetic and observed acceleration spectra at 6 near-source stations. NS and WE horizontal components are plotted with dashed and solid thin lines, respectively. DSM synthetics are plotted with solid thick line.

Another limitation of the classical PSHA formulation is that the earthquake effects are described by predictive empirical equations providing the required ground motion estimates as a function of parameters like the earthquake magnitude, the source-to-site distance, the site conditions (e.g., Sabetta and Pugliese, 1996; Abrahamson and Silva, 1997). However, the empirical models account only roughly for source properties (in general, through the magnitude and in some case by a coefficient that depends on the receiver's position with respect to the fault; i.e. hanging-wall or foot-wall recording sites), propagation (through the distance), and site effects (through a coefficient). This representation of the source contribution does not account for the variability of the radiated ground motions that we have shown before. In other words, this representation of the source contribution is reliable only for recording sites located at distances from the source larger of equal to the fault dimension (far field, far source approximation). We emphasize that near source radiation requires us to account for the source complexity and dynamic heterogeneity in order to properly model the high frequency (larger than $1 \mathrm{~Hz}$ ) ground motions. To this goal the method proposed by Convertito et al. (2006) takes into account the effects of rupture history and source heterogeneities through deterministic modelling of the waveforms radiated by an extended fault. In the following we discuss the application of this modified PSHA approach to the Colfiorito main shock.

In the framework of the classical PSHA approach, the hazard is evaluated computing the hazard integral (Cornell, 1968) that, for the i-th seismic source zone, provides the frequency of 
exceedance $\mathrm{E}_{\mathrm{i}}$ of a fixed threshold value $\mathrm{A}_{0}$ for a given ground motion parameter $\mathrm{A}$ as

$$
\begin{aligned}
& E_{i}\left(A \geq A_{0}\right)=\alpha_{i} \int_{R} \int_{M} f_{R}(r) f_{M}(m) . \\
& p\left[A(m, r) \geq A_{0} \mid m, r\right] d r d m
\end{aligned}
$$

where $f_{R}(r) d r$ represents the probability of occurrence of an earthquake at a distance between $\mathrm{r}$ and $\mathrm{r}+\mathrm{dr}$ from the target site. The probability density function $f_{R}(r)$ has no analytical formulation except that in simple cases. The Probability Density Function $\mathrm{f}_{\mathrm{M}}(\mathrm{m})$ provides the probability of occurrence of an earthquake having a magnitude in the range $(m, m+d m)$. Finally, the coefficient $\alpha_{i}$ represents the average rate of earthquake occurrence for the ith seismogenetic zone and, in general, is estimated from seismic catalogues.

If a single causative fault is considered for a scenario-like analysis, the hazard integral needs some modifications because the PDFs $f_{R}(r)$ and $\mathrm{f}_{\mathrm{M}}(\mathrm{m})$ and the seismic activity rate $\alpha_{\mathrm{i}}$ have no obvious formulations. First of all, considering that the fault geometry is known (table I), and assuming that the rupture process at the source involves the whole fault plane, we can use a definition of distance as the minimum distance from the surface projection of the fault plane (Joyner and Boore, 1981). In this way, for any given receiver, the source-to-site distance is fixed aside from the location of the nucleation point and then there is no more need to consider a PDF for it in the hazard integral. If the characteristic-earthquake model is assumed, the PDF $f_{M}(m)$ is characterized by a constant probability of occurrence of earthquakes having magnitude in the neighborhood of the magnitude of the characteristic earthquake (M6.0 for the Colfiorito fault). Moreover, the characteristic earthquake dos not occur at the exclusion of other size events that are accounted in the PDF $\mathrm{f}_{\mathrm{M}}(\mathrm{m})$ as non-characteristic part. In other words, the $f_{M}(m)$ is a truncated exponential up to the characteristic magnitude value and it is constant for larger magnitudes (see the fig. 1 in the paper by Convertito et al., 2006). In the same way, Youngs and Coppersmith (1985) provide the expressions for evaluating the seismic activity rates both for the non-characteris- tic and characteristic parts of the PDF $\mathrm{f}_{\mathrm{M}}(\mathrm{m})$.

In conclusion, the hazard integral for a given site located at a distance $r^{*}$ from the surface projection of the fault plane can be rewritten (Convertito et al., 2006), in the case of the characteristic-earthquake model, as

$$
\begin{aligned}
& E\left(A \geq A_{0}\right)=\alpha_{c} \int_{m_{c}}^{m_{c}+\Delta m} f_{M}^{c}(m) . \\
& p\left[A\left(m, r^{*}\right) \geq A_{0} \mid m, r^{*}\right] d m
\end{aligned}
$$

$\mathrm{m}_{\mathrm{c}}$ being the 'characteristic' magnitude while $\Delta \mathrm{m}$ defines the range in which the fault behaviour can be considered characteristic. Youngs and Coppermith (1985) suggested $\Delta \mathrm{m}=0.5$.

For evaluating the frequency of exceedance $E$ through the computation of the hazard integral (equation 2), the level reached by the selected ground motion parameter A and the associated probability of exceedance $p$ of the threshold value $\mathrm{A}_{0}$ are needed. For this purpose, the scenario study performed for the Colfiorito fault allows the computation of the earthquake effects, in terms of PGA, assuming a log-normal statistical distribution for the selected ground motion parameter. In particular, we used the mean PGA and the associated variability inferred from the whole set of rupture processes simulated varying the slip distribution and the position of the nucleation point. The maps of PGA and of the associated Coeffi-

cient of Variation $\left(C o V=\frac{100 \sigma_{P G A}}{<P G A\rangle}\right)$ we used are shown in fig. 9. The $\mathrm{CoV}$ parameter is a way to show how the variability at the source in transferred to the ground motion variability.

As an example, we shown in fig. 10 the hazard map obtained by the approach proposed by Convertito et al. (2006) when the characteristic earthquake model is assumed, for a return period $\mathrm{T}=50,000$ years. In the same figure it is also reported for comparison the hazard map computed by using the Abrahamson and Silva (1997) ground motion predictive equation for PGA. We used the Abrahamson and Silva (1997) empirical equation in order to separate sites locate in the fault foot-wall from those lo- 


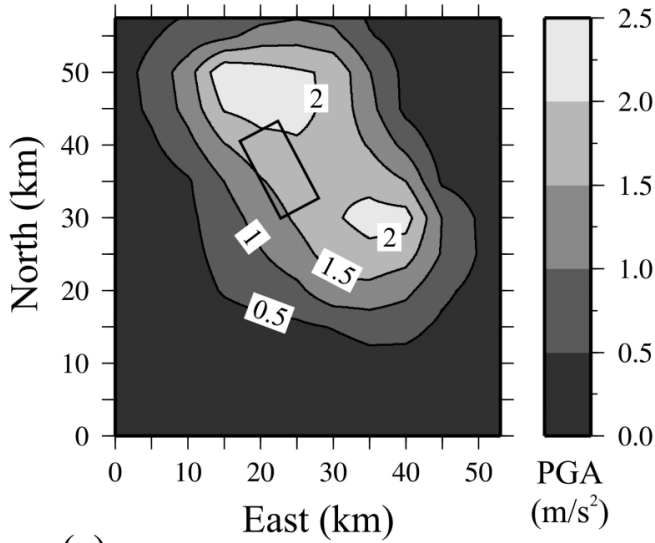

(a)

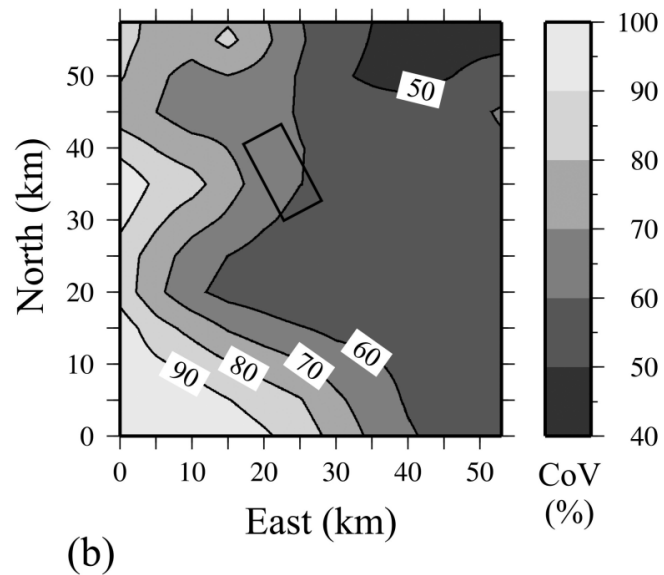

(b)

Fig. 9. (a) Map of simulated PGA (mean values). (b) Map of the Coefficient of Variation. Results were obtained by the ASM simulation technique. The rectangles in the figures represent the surface projection of the fault (modified after Convertito et al., 2006).
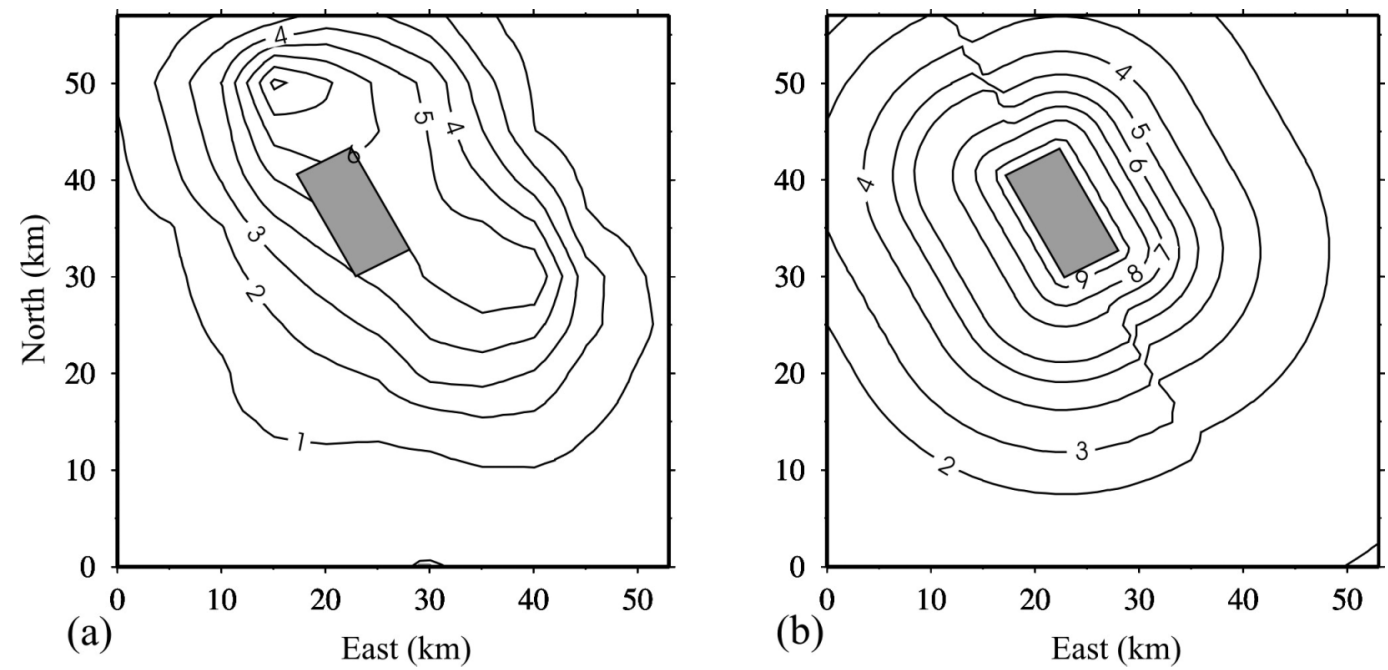

Fig. 10. Hazard map for PGA associated with the Colfiorito fault and corresponding to $T=50,000$ return period. Contour lines for PGAs larger then $1 \mathrm{~m} / \mathrm{s}^{2}$ are shown. The grey rectangles represent the surface projection of the fault. (a) Hazard map for the characteristic earthquake model and PGAs simulated by the ASM technique. (b) Hazard map for the characteristic earthquake model and PGAs estimated by the Abrahamson and Silva (1997) predictive relation. (modified after Convertito et al. 2006).

cated in the hanging-wall. The hazard map obtained from synthetic PGAs reproduces the main features of the mean PGA map of fig. 9, thus accounting for the kinematic source parameters (fault geometry, radiation pattern, and directivity). 


\section{Conclusive remarks}

The geophysical data collected during the Umbria-Marche, Italy, seismic sequence (199798) represent a unique database which allows us to improve the seismic hazard assessment for the region. In particular, strong ground motion records of the Colfiorito main shock (September $26^{\text {th }}, 1997,9: 40$ UTC, $\left.M_{w} 6.0\right)$ reveal that stations located north of the epicenter recorded peak accelerations systematically larger then those recorded at stations located to the south (Cultrera et al., 2008). Moreover, the accelerograms recorded at NCR (Nocera Umbra) and CLF (Colfiorito) are characterized by a relatively high peak ground acceleration, not captured by empirical predictive models. The former observation suggests that rupture directivity toward the NW played a dominant role, while the second observation can be explained in terms of local site amplifications.

The activities performed in the framework of the GNDT Project gave us the opportunity to investigate the observed pattern of ground motion waveforms and to perform a systematic study on ground shaking scenarios comparing different simulation techniques. In this paper, we present the main results of this simulation attempts and the computed shaking scenarios for the Colfiorito earthquake using two simulation techniques, i.e., ASM (Zollo et al., 1997) and DSM (Pacor et al., 2005).

The variability of ground motion parameters obtained with both techniques is comparable or smaller than the standard deviation associated with the empirical predictive model UMA2005 (Bindi et al., 2006), even if both simulation methods are approximated. As expected, our modeling results are strongly dependent on the position of nucleation point (directivity effect), on faulting style and on the adopted rupture velocity value: the higher the rupture velocity the higher the peak ground motions.

The ground motions observed during the Colfiorito earthquake are well reproduced when an unilateral rupture propagation toward the NW is considered, with a rupture velocity of about $2.7 \mathrm{~km} / \mathrm{s}$. The data can be modeled only in some particular frequency bands due to the relevant amplification associated with the site effects, which require the use of appropriate site transfer functions in the modeling. In general, the scenario studies preformed for the Colfiorito earthquake highlighted that the extended fault effects (e.g., the rupture directivity) are important also in the case of moderate size earthquake. This conclusion encouraged us to carry out a systematic study on the ground motion variability due to the source parameters for moderate magnitude earthquakes, which was performed in the framework of the S3 Project.

The inferred main source features of the Colfiorito earthquake have also been used in a recent technique aimed at integrating probabilistic and deterministic approaches for seismic hazard assessment. The deterministic approach allows us to compute ground shaking scenarios for an earthquake occurring on a given, well known, causative fault. In the case of the Colfiorito scenarios, we have shown that it is possible in this way to properly include source and propagation effects in simulated ground motions. On the other hand, the deterministic scenarios represent a sort of 'static' results that are of poor use for probabilistic hazard assessment, because it is not possible to include the earthquake recurrence time in the computation.

The technique proposed by Convertito et al. (2006) is based on the site-dependent evaluation of the probability of exceedance for the chosen strong motion parameters (e.g., peak quantities, and spectral ordinates). The probability is obtained from the statistical analysis of the synthetic waveforms data base produced for a large number of possible rupture histories occurring on a characteristic earthquake fault. The integrated technique is aimed at overcoming some of the limitations of both purely probabilistic and purely deterministic approaches for seismic hazard assessment. In particular, it allows us to account for the return period and elapsed time in the deterministic scenarios and for the source characteristics and their effects on the ground motions (as the geometry, the radiation pattern, and the directivity) in the probabilistic technique. Due to the availability of synthetic seismograms, the analysis can be extended to any desired ground motion parameter. Moreover, the site effects can be easily taken into account if the transfer functions are available. 
The combined study of a deterministic and a probabilistic approaches to compute ground shaking scenarios for the Colfiorito earthquake allows us to point out the importance of sourceto-receiver geometry and heterogeneity of source parameters on extended faults also for moderate magnitude seismic events. Indeed, despite the small dimension of the causative faults, the directivity effects strongly affect the observed pattern of PGA values. Once rupture directivity is properly taken into account, the deterministic simulation methodologies are able to reproduce the average Fourier spectra of ground acceleration, the spatial pattern of recorded PGA as well as the variability of ground motion parameters with distance. This corroborates the relevance of including the outcomes of deterministic ground motion predictions in probabilistic hazard assessment to specific target sites.

\section{Acknowledgments}

The research activities presented in this article were supported by the projects «Sviluppo e confronto di metodologie per la valutazione della pericolosità sismica in aree sismogenetiche: applicazione all'Appennino centrale e meridionale», GNDT 2000-2003, and «Scenari di scuotimento e di danno atteso in aree di interesse prioritario e/o strategico», S3 Project, DPC-INGV 2004-2006. The authors thank all the people (such as D. Bindi, G. Festa, L. Luzi, E. Priolo, A. Saraò, P. Suhadolc, and A.Vuan, among many others) involved in these projects who collaborate to the simulation studies related to the Colfiorito earthquake. The careful revision made by J. Burianek and anonymous reviewer improved the manuscript. We also thank the Editorial Board of Annals of Geophysics that welcomed our paper.

\section{REFERENCES}

Abrahamson, N. A. and W. J. Silva (1997): Empirical response spectral attenuation relations for shallow crustal earthquakes, Seism. Res. Lett., 68, 94-127.

Bernard, P., and R. Madariaga (1984): A new asymptotic method for the modelling of near-field accelerograms, Bull. Seism. Soc. Am., 74, 539-555.

Bindi, D., R. R. CAStro, G. Franceschina and F. Pacor
(2004): The 1997-1998 Umbria-Marche sequence (central Italy): Source, Path and Site effects estimated from strong motion data recorded in the epicentral area, J. Geophys. Res., 109, B04312, doi: 10.1029/2003JB002857.

Bindi, D., L. Luzi, F. Pacor, G. Franceschina and R. R. CASTRO (2006): Ground-motion predictions from empirical attenuation relationships versus recorded data: the case of 1997-1998 Umbria-Marche, central Italy, strongmotion data set, Bull. Seism. Soc. Am., 96, 984-1002, doi:10.1785/0120050102.

Capuano, P., A. Zollo, A. Emolo, S. Marcucci and G. Milana (2000): Rupture mechanism and source parameter of Umbria-Marche main shocks from strong motion data, J. Seism., 4, 436-478.

Convertito V., A. Emolo and A. Zollo (2006): Seismic-hazard assessment for a characteristic earthquake scenario: an integrated probabilistic-deterministic method, Bull. Seism. Soc. Am., 96, 377-391, doi: 10.1785/0120050024.

Cornell, C.A. (1968): Engineering seismic risk analysis, Bull. Seism. Soc. Am., 58, 1583-1606.

Cultrera, G., A. Rovelli, G. Mele, R. Azzara, A. CaserTA and F. MARRA (2003): Azimuth-dependent amplification of weak and strong round motions within a fault zone (Nocera Umbra, central Italy), J. Geophys. Res., 108, 2156, doi: 10.1029/2002JB001929.

Cultrera, G., F. Pacor, G. Franceschina, A. Emolo and M. Cocco (2008): Directivity effects for moderatemagnitude earthquakes (Mw 5.6-6.0) during the 1997 Umbria-Marche sequenze, central Italy, in press on Techtonophysics, doi: 10.1016/j.tecto.2008.09.22.

Di Giulio, G., A. Rovelli, R. Cara, R.M. AzZara, F. MarRA, R. BASILI, and A. CASERTA (2003): Long-duration asynchronous ground motions in the Colfiorito plain, central Italy, observed on two dimensional dense array, $J$. Geophys. Res., 108, 2486, doi: 10.1029/2002JB002367.

FARra, V., P. Bernard and R. MAdariaga (1986): Fast near source evaluation of strong ground motion for complex source models, in Earthquake source mechanics, S. DAs, J. BoATwright and C.H. SchOlZ Eds., American Geophysical Monograph, 37, 121-130.

Hernandez, B., M. Cocco, F. Cotton, S. Stramondo, O. Scotti, F. Courboulex, and M. CAMpillo (2004): Rupture history of the 1997 Umbria-Marche (central Italy) main shocks from the inversion of GPS, DInSAR, and near field strong motion data, Ann. Geophys. 47, 1355-1376.

Herrero, A. and P. BERNARd (1994): A kinematic self-similar rupture process for earthquakes, Bull. Seism. Soc. Am., 84, 1216-1229.

JoYNER, W.B. and D.M. Boore (1981): Peak horizontal acceleration and velocity from strong-motion records including records from the 1979 Imperial Valley, California, earthquake, Bull. Seism. Soc. Am., 71, 2011-2038.

Luzi, L., D. Bindi, G. Franceschina, F. Pacor, and R.R. CASTRO (2005): Geotechnical site characterisation in the Umbria Marche area and evaluation of earthquake site-response, Pure and Appl. Geoph., 162, 2133-2161.

Pacor, F., G. Cultrera, A. Mendez and M. Cocco (2005): Finite fault modelling of strong ground motion using a hybrid deterministic-stochastic approach, Bull. Seism. Soc. Am., 95, 225-240, doi: 10.785/0120030163.

Pantosti, D. and G. VAlensise (1990): Faulting mechanism and complexity of the November 23, 1980, Cam- 
pania-Lucania earthquake, inferred from surface observations, J. Geophys. Res., 95, 15319-15341.

Pino, N. A., S. MazzA, and E. Boschi (1999): Rupture directivity of the major shocks in the 1997 Umbria-Marche (central Italy) sequence from regional broadband waveforms, Geophys. Res. Lett., 26, 2101-2104.

Rovelli, A., L. Scognamiglio, F. Marra and A. Caserta (2001): Edge-diffracted 1-sec surface waves observed in a small-size intramountain basin (Colfiorito, central Italy), Bull. Seism. Soc. Am., 91, 1851-1866.

Sabetta, F. and A. Pugliese (1996): Attenuation of peak horizontal acceleration and velocity from Italian strongmotion records, Bull. Seism. Soc. Am., 86, 337-352.

SCHWARTZ, D.P. and J. COPPERSMITH (1984): Fault behavior and characteristic earthquake: example from Wasatch and San Andreas faults, J. Geophys. Res., 89, 5681-5698.
SPUDich, P. and L.N. FraZer (1984): Use of ray theory to calculate high-frequency radiation from earthquake sources having spatially variable rupture velocity and stress drop, Bull. Seim. Soc. Am., 74, 2061-2082.

Youngs, R. R. and J. COPPERSMITH (1985): Implications on fault slip rates and earthquake recurrence models to probabilistic seismic hazard estimates, Bull. Seism. Soc. Am., 75, 939-964.

Zollo, A., A. Bobbio, A. Emolo, A. Herrero and G. De NATALE (1997): Modeling of ground acceleration in the near source range: the case of 1976, Friuli earthquake (M=6.5), Northern Italy, J. Seism., 1, 305-319.

Zollo, A., S. Marcucci, G. Milana and P. Capuano (1999): The 1997 Umbria-Marche (central Italy) earthquake sequence: insights on the main shock ruptures from near source strong motion records, Geophys. Res. Lett., 26, 3165-3168. 